\title{
Uma perspectiva reducionista da revolução keynesiana: a síntese neoclássica ${ }^{1}$
}

Maria Isabel Busato*

Eduardo Costa Pinto**

Resumo: Este artigo tem por finalidade desenvolver, numa perspectiva póskeynesiana, uma análise crítica da síntese neoclássica, tentando mostrar que (I) suas hipótesestêm pouca relevância para a análise do mundo real e que (II) sua interpretação keynesiana representou muito mais um retorno aos axiomas neoclássicos do que uma verdadeira leitura dos elementos centrais da revolução de Keynes. Para tanto, procuramos explorar uma linha de caracterização teórica dos principais formuladores da síntese neoclássica (Hicks e seu modelo IS-LM ; Modigliani e o Efeito Keynes; Patinkin e o Efeito Pigou), identificando suas restrições, tanto no que diz respeito a sua identificação com a teoria original de Keynes, como no que se refere a sua interpretação do sistema econômico.

Palavras-chave: Revolução Keynesiana, Síntese Neoclássica, IS-LM, Efeito Keynes e Pigou, Keynesianismo.

Abstract: This article develops, in a post-keynesian perspective, a critical analysis of the neoclassical synthesis, trying to show that (I) its hypotheses have little relevance for the analysis of the real world and that (II) its keynesian interpretation represents much more a return to the neoclassical axioms than a true reading of the central elements of the Keynesian revolution. In this way, we analyze the contributions of the main formulators of the neoclassical synthesis (Hicks and its model IS-LM; Modigliani and the Keynes effect; the Patinkin and Pigou "effects"), identifying their shortcomings in interpreting both Keynes's theory and the functioning of the economic system itself.

Keywords: Keynesian Revolution, Neoclassical Synthesis, IS-LM, Effect Keynes and Pigou, Keynesianism.

J EL Classification: B22; E12; E13.

1 Os autores agradecem aos pareceristas anônimos da Revista Análise Econômica.

* Doutoranda em Economia pela Universidade Federal do Rio de J aneiro (IE/UFRJ ); Professora Substituta da Universidade Federal Fluminense UFF; Mestra em economia pela Universidade Federal da Bahia (CME/UFBA); bolsista CNPq; E-mail: mariaisabelbusato@yahoo.com.br

** Doutorando em Economia pela Universidade Federal do Rio de J aneiro (IE/UFRJ ); bolsista FAPERJ ; Mestre em economia pela Universidade Federal da Bahia (CME/UFBA); E-mail: eduardopintobr@yahoo.com.br 


\section{Introdução}

0 ano de 2006 foi marcado pelos 70 anos da publicação de uma das mais importantes obras econômicas do século XX. A teoria geral do emprego, do juro e da moeda, de autoria de J ohn Maynard Keynes. Esta obra constituiu-se num marco divisório para o estudo da economia. Existem duas formas interpretativas da ciência econômica, uma anterior e uma posterior à publicação da Teoria Geral (TG). Na verdade, as idéias expostas na TG conformaram um novo paradigma científico no âmbito da economia, influenciando assim grande parte da tradição macroeconômica moderna.

0 arcabouço teórico exposto na TG, portanto, pode ser enquadrado como uma "revolução científica", ${ }^{2}$ uma vez que tal constructo descartou os principais axiomas e os princípios básicos da teoria (neo) clássica, do mundo da lei de Say, até então dominante, e forneceu novos axiomas para uma teoria alternativa, coerente e consistente. Para Keynes, os postulados da teoria neoclássica (paradigma anterior) não eram aplicáveis ao caso de uma teoria geral do sistema econômico, além do que eles não correspondiam à economia monetária da produção em que vivemos. Sendo assim, a revolução keynesiana rejeitou os principais axiomas ${ }^{3}$ anteriores, quais sejam: (i) da substituição bruta (perfeita substituibilidade entre fatores de produção, tais como capital e trabalho); (ii) axioma dos reais (a dicotomia dos fenômenos econômicos, em que as variáveis nominais seriam incapazes de afetar as variáveis reais); e (iii) de um mundo econômico ergódico. ${ }^{4}$

A revolução keynesiana na teoria econômica foi uma revolta - pois visava substituir postulados e rejeitar princípios básicos então dominantes - que forneceu os fundamentos lógicos de um modelo que negava a lei de Say e se relacionava mais de perto com o mundo real [...] (DAVIDSON , 2003, p. 4).

20 conceito de "revolução científica" aqui empregado não deve ser vinculado, exclusivamente, à idéia de revolução científica de Kuhn em que um novo paradigma acaba por eliminar o anterior. Nas ciências sociais isso não acontece, pois há uma coexistência generalizada de pontos de vistas diferentes. Com isso, apesar da maneira nova e mais consistente de Keynes para a compreensão do sistema econômico (mundo real), mostrando inclusive as inconsistências lógicas da visão neoclássica, o antigo paradigma econômico de pensar não desapareceu e continuou vivo. Essa coexistência, em certa medida, conflituosa entre paradigmas acontece em virtude da impossibilidade de uma construção metodológica neutra no âmbito dos estudos na ciência social, inclusive no ramo da economia.

3 Para uma discussão mais detalhada a respeito da rejeição da revolução keynesiana aos axiomas neoclássicos ver Davidson (1985; 2003).

40 termo ergódico refere-se à condição segundo a qual, após ter sido submetida a algum choque exógeno, o sistema retorna a estados muito similares aos precedentes, decorrido um intervalo de duração suficiente (DAVIDSON, 2003, p. 5). 
Ao buscar uma teorização adequada das características do mundo real (economia monetária de produçã $0^{5}$ ), Keynes abandonou tanto a idéia de que o pleno emprego é um estado normal de uma economia de mercado como a suposição clássica de que existem forças endógenas que proporcionam a plena ocupação dos fatores de produção na economia. Ele, na verdade, empenhou-se em demonstrar que o sistema econômico é potencialmente instável e que tais instabilidades potenciais constituem o estado em uma economia monetária de produção, na qual as decisões são tomadas sob incerteza, a oferta reage à demanda e a moeda afeta as decisões dos indivíduos em seus desejos de investir, entesourar ou de postergar tais disposições. Influenciando, em última instância, o nível de demanda, as decisões de investir, o produto e o emprego (WELLS, 1987, p. 88-9).

Desse modo, Keynes estabeleceu uma teoria geral da determinação do produto e do emprego por meio da teoria da renda (propensão a consumir e multiplicador da renda), da teoria dos investimentos (eficiência marginal do capital) e da teoria da taxa de juros (preferência pela liquidez). Quando construiu tais inovações, ele formulou uma teoria macroeconômica geral que levou em conta as diversas situações, inclusive a situação limite de equilíbrio com pleno emprego, definido como o caso especial da teoria clássica. Como conseqüência da regra comum da economia operar abaixo do pleno emprego, abriuse um caminho permanente para a atuação do governo, que deveria ser pautada pela configuração e pela adoção de políticas econômicas destinadas a alavancar a demanda agregada e a reduzir as incertezas econômicas, estimulando assim a realização de novas inversões pelos empresários.

Apesar da alternativa coerente e consistente da TG de Keynes, ela não escapou ilesa ao contra-ataque neoclássico. Muito pelo contrário, pois, já em 1937 - em menos de dois anos após a publicação da Teoria Geral - Hicks, em seu artigo “Mr. Keynes and the Classics: A

5 As principais características de uma economia monetária da produção são (i) a não-neutralidade da moeda no processo produtivo tanto no curto quanto no longo prazo, de tal modo que a moeda afeta a tomada de decisões relativas às variáveis reais; (ii) a irreversibilidade do tempo e a incerteza, haja vista que não existe reversão de planos e processos sem custos em uma economia monetária de produção, por isso, a tomada de decisões pelos agentes é realizada através de conjecturas (expectativas futuras), já que as informações não são perfeitas nem probabilísticas. Assim, a incerteza ganha papel central na análise econômica. A partir desses elementos fica claro que Keynes propõe um enfoque metodológico diferente do viés axiomático-dedutivo típico do mainstream do pensamento econômico (teoria neoclássica). Os princípios acima listados funcionam como instruções básicas para a montagem de explicações (modelos) da economia capitalista, fundamentando o enfoque de demanda efetiva em características dos processos de decisão relevantes do sistema (CARVALHO, 1992a, 1992b). 
suggested interpretation", pavimentou o caminho para uma das primeiras interpretações "neoclassizadas" de Keynes, a saber: a síntese neoclássica que veio, durante as duas décadas que se seguiram à publicação da TG, tentando negar o caráter geral da teoria keynesiana - buscando transformá-la num caso particular do modelo (neo)clássico - por meio do modelo de equilíbrio geral walrasiano, articulando-o à idéia de imperfeições temporárias do mecanismo de mercado provenientes da rigidez de preços e/ou salários nominais. Além de Hicks, a síntese neoclássica foi desenvolvida basicamente por Modigliani, Patinkin, Hansen e Samuelson. É preciso destacar que a síntese neoclássica foi e ainda é uma das mais influentes interpretações da teoria de Keynes.

Este artigo tem por finalidade desenvolver uma análise crítica da síntese neoclássica, tentando mostrar que (i) suas hipóteses têm pouca relevância para a análise do mundo real e que (ii) sua interpretação keynesiana representou muito mais um retorno aos axiomas neoclássicos do que uma verdadeira leitura dos elementos centrais da revolução keynesiana (princípio da demanda efetiva e a incerteza quanto ao devir). Para tanto, procurar-se-á explorar uma linha de caracterização teórica de alguns dos principais formuladores da síntese neoclássica (Hicks e seu modelo IS-LM; ${ }^{6}$ Modigliani e o Efeito Keynes; Patinkin e o Efeito Pigou), ${ }^{7}$ apresentando suas restrições, tanto no que diz respeito a sua identificação com a teoria original de Keynes, como no que se refere a sua interpretação do sistema econômico capitalista.

Metodologicamente, a abordagem aqui adotada tem um caráter histórico-teórico centrado na descrição e na análise da leitura da obra de Keynes realizada pelos autores da síntese neoclássica. Ao adotar tal caminho parte-se da idéia de que

o progresso científico em teoria econômica não pode prescindir de retornos periódicos ao passado. Em outras palavras, pretendemos chamar a atenção para o fato de que a história da teoria econômica não pode ser vista como algo que se preste somente ao deleite arqueológico daqueles

6 Cabe observar que por volta dos anos 70 Hicks tentou fazer uma ruptura com essa publicação de 1937, afirmando que o diagrama IS-LM expressa muito pouco daquilo que Keynes quis realmente dizer. Veja Hicks (1980-1981).

7 Apesar de inúmeras contribuições feitas à síntese neoclássica depois de Hicks, nos restringiremos, neste artigo, às análises dos trabalhos desenvolvidos pelo próprio Hicks, por Modigliani e por Patinkin. Mesmo tendo claro que estes autores estão longe de esgotar todas as possíveis análises da síntese, eles pavimentaram os caminhos para o desenvolvimento analítico de outros autores. Por conseguinte, representam boa parte das idéias expostas nessa corrente macroeconômica. 
interessados em organizar o (de outro modo) confuso arquivo da história. Ao contrário, acreditamos que o progresso da própria teoria econômica tem na história das idéias passadas (cronologicamente falando) uma fonte significativa de estímulos para o processo de auto-reflexão ao qual ela deve recorrentemente se submeter. Libertar a ciência econômica do reducionismo imobilista ao qual foi reduzida pela epistemologia positivista, onde a razão é concebida apenas na sua dimensão instrumental, nos parece absolutamente fundamental para que avancemos no sentido de promover a necessária retomada de sua consciência reflexiva (TADEU LIMA, 1992, p. 17).

Além desta introdução, descrevem-se de forma crítica, na segunda seção deste artigo, os elementos basilares da síntese neoclássica, destacando, sobretudo, a contribuição e os problemas do modelo IS-LM de Hicks; a incorporação do Efeito Keynes por Modigliani; a inclusão do efeito Pigou ao modelo desenvolvido por Patinkin, tanto em sua perspectiva estática quanto dinâmica. Por fim, na terceira seção, procura-se alinhavar algumas idéias conclusivas.

\section{0 s elementos basilares da síntese neoclássica: 0 início da "neoclassização" da Teoria G eral}

Os autores da síntese neoclássica, a despeito de sua origem keynesiana, continuaram a acreditar, tais como os economistas clássicos, que o equilíbrio com pleno emprego seria o estado normal de uma economia de mercado, haja vista a existência de forças endógenas (Efeito Keynes, Efeito Pigou-Patinkin, etc.) de convergência em direção à posição de pleno emprego dos fatores produtivos. Em outras palavras, nesse modelo, o market clearing - perfeita flexibilidade dos preços e salários simultâneo em todos os mercados, inclusive no de trabalho - levaria à configuração de um equilíbrio com pleno emprego. No entanto, o keynesianismo neo-clássico admite, ainda que temporariamente, que essas forças endógenas de convergência podem ser contrapostas pela existência de diversas formas de rigidezes de preço e/ou salários e de outras imperfeições; desse modo, assume-se a existência da situação de equilíbrio com excesso de oferta de trabalho no curto prazo e, conseqüentemente, situações Paretoinferiores com produto abaixo do potencial (LIMA, 2003; SICSÚ \& MENDONÇA, 2000; OREIRO, 1997).

A síntese neoclássica, portanto, busca comprovar que o maior avanço de Keynes não foi ter desenvolvido uma contribuição analítica da demanda efetiva, da preferência pela liquidez e do papel da incerteza no âmbito da economia monetária da produção, mas sim 
teria sido, simplesmente, alertar para os mecanismos que obstaculizam o alcance do factível equilíbrio de pleno emprego no curto prazo. Nessa perspectiva, a revolução keynesiana ficou reduzida a um mero caso particular do modelo (neo)clássico (LIMA 2003).

Assim, o keynesianismo neoclássico buscou validar a teoria clássica como o caso geral, particularizando a teoria keynesiana para as situações nas quais: i) a economia estivesse na armadilha da liquidez; ii) a demanda por investimento fosse insensível à taxa de juros (evitando a igualdade entre poupança e investimento ao nível de renda de pleno emprego); iii) vigorasse algum tipo de obstáculo que impedisse que o salário e/ou preços caísse para a economia alcançar o pleno emprego (LIMA, 1992 e 2000). Dentre estas, a situação (iii) é a considerada, pelos autores da síntese, como o principal impedimento temporário para a convergência ao pleno emprego, ou seja, essas rigidezes acabariam obstaculizando os mecanismos de mercado, impedindo o ajuste rápido entre o produto efetivo e o potencial.

\subsection{A estrutura lógica do modelo de Hicks: ${ }^{8}$ os limites do instrumental IS-LM}

Hicks (1978), a partir de algumas equações e diagramas, tentou apresentar elementos de junção e diferenciação entre as teorias clássica e keynesiana, ensejando construir um modelo mais geral (uma síntese das teorias). A interpretação sugerida por J ohn Hicks foi amplamente popularizada como a expressão do pensamento keynesiano, até por que a formalização e o determinismo, característicos de seu modelo, tornaram a leitura da TG menos árida, porém bem menos realista. Segundo Young (1987), a disseminação desses modelos macroeconômicos originários da síntese neoclássica devese ao fato de serem determinísticos, simétricos e sem incerteza. $\mathrm{Na}$ perspectiva hicksiana, a teoria de Keynes seria útil apenas para analisar um caso específico, ${ }^{9}$ qual seja, períodos de recessão em que a elasticidade juros demanda por moeda tenderia para 0 infinito: ${ }^{10} 0$ caso da armadilha da liquidez.

Dessa feita, Hicks (1978) teria supostamente construído um ferramental analítico que possibilitaria a construção de uma "verdadeira"

8 Ao longo dessa subseção utilizaremos o texto clássico de J. Hicks (1978) "Mr Keynes and the Classics: An suggest interpretation".

9 Tal visão foi flexibilizada pelos teóricos que desenvolveram o modelo IS-LM a partir de Hicks, na medida em que eles combinaram desemprego involuntário com situações em que a economia não esteja na armadilha da liquidez (LM positivamente inclinada).

$10[(\partial \mathrm{M} D / \partial i) \square \infty] \mathrm{A}$ variação na quantidade demandada de moeda em resposta à variação na taxa de juros é infinita e a curva LM horizontal. 
teoria geral. Segundo ele não há uma contradição entre as teorias clássica e keynesiana. Tal posição ficou bastante clara já no início de seu artigo: "[...] Há, realmente, alguma diferença entre elas [a contribuição de Keynes e a de Marshall] ou será tudo uma luta fingida?" (HICKS, 1978, p. 211).

Para construir seu modelo, Hicks utilizou-se das seguintes equações ${ }^{11}$ clássicas e keynesianas,

Equações do Modelo Clássico:

Equações do Modelo keynesiano:

$$
\mathrm{M}=\mathrm{kY} ; \mathrm{I}=\mathrm{I}(\mathrm{i}) ; \mathrm{I}=\mathrm{S}(\mathrm{Y}, \mathrm{i})
$$

$$
\mathrm{M}=\mathrm{L}(\mathrm{i}) ; \mathrm{I}=\mathrm{I} ; \mathrm{I}=\mathrm{S}(\mathrm{Y})
$$

Equações do Modelo de equilíbrio geral hicksiano:

$$
M=L(Y, i) ; I=I(Y, i) ; I=S(Y, i)
$$

as quais representam, o mercado monetário, o mercado de bens e o de ativos, em que $M$ é a quantidade de moeda, $k$ é o inverso da velocidade da circulação da moeda (conforme equação quantitativa de Cambridge), Y é a renda total, I o investimento agregado, i a taxa de juros (no caso keynesiano não diferirá se real ou nominal, já que os preços estão fixos), e S é a poupança.

Ao descrever o modelo de Keynes, Hicks levanta a hipótese de que o mesmo precisaria ser revisto, em virtude da necessidade de incluir a renda, além da taxa de juros, como determinante da demanda por moeda. Ou seja, para Hicks, Keynes teria deixado de lado o motivo transação na determinação da demanda por moeda. Em suas próprias palavras "[...] não importa quanto realce venhamos a dar ao 'motivo especulativo'; o motivo das 'transações' também deverá ser considerado" (HICKS, 1978, p. 211). Ocorre que quando Keynes escreveu a Teoria Geral estava claro que pretendia fazer uma teoria da determinação do nível de atividade e, portanto, do emprego. Ora, sendo esse o objetivo, um dos pontos fundamentais que explica a existência de desemprego involuntário é a parte subtraída da demanda, resultante da demanda por moeda pelo motivo especulação, que guarda, por sua vez, fundamental relação com a incerteza e com as taxas efetiva e esperada de juros. Além disso, nos capítulos 15 e 18 da TG, Keynes explicita que a demanda por moeda para especulação é inversamente relacionada aos movimentos efetivos e esperados da taxa de juros.

11 Foram feitas algumas adaptações na simbologia das equações do artigo clássico de Hicks a fim de torná-las mais próximas da forma como vem sendo apresentado na literatura macroeconômica atual, tais como em Blanchard (1999), Lopes \& Vasconcelos (2000) e Mankiw (1995). 
Desse modo, Keynes dá maior ênfase ao motivo especulação porque a moeda quando retirada de circulação não se transforma em demanda efetiva, afetando as expectativas dos agentes, o que, por sua vez, constitui um dos motivos que levam a economia a operar com desemprego involuntário. Além disso, o aumento da preferência pela liquidez dos agentes econômicos (principalmente bancos e instituições financeiras) induz a elevação das taxas de juros que desestimula a decisão de investir dos agentes (KEYNES, 1984). Esses elementos, por sua vez, se constituem em alguns dos motivos que levam a economia a operar com desemprego involuntário. Já a demanda por moeda para transação, ${ }^{12}$ que depende da renda e, marginalmente, da taxa de juros, em algum momento curto se transformará em demanda. Além disso, a demanda para transações é sempre muito mais estável.

Em circunstâncias normais, o volume de moeda necessário para satisfazer os dois motivos, transação e precaução, é, principalmente, o resultado da atividade geral do sistema econômico e do nível da renda nacional em termos monetários. Todavia, a administração monetária (ou, em sua ausência, as mudanças fortuitas que podem advir da quantidade de moeda) faz sentir seu efeito sobre o sistema econômico por sua influência sobre o motivo-especulação. Isso porque a demanda de moeda para satisfazer os motivos anteriores [transação e precaução] é, em geral, insensível a qualquer influência que não a de uma alteração efetiva na atividade econômica geral e no nível da renda, ao passo que a experiência mostra que a demanda de moeda para satisfazer o motivo-especulação varia de modo contínuo sob o feito de uma alteração gradual na taxa de juros [...] (KEYNES, 1982, p. 158).

Assim, a dependência da demanda por moeda da renda não é fator de desestabilização do sistema, pelo contrário, tal demanda gera gastos em bens e serviços. Para Ferrari (2003), a utilização da demanda por moeda, dependente da renda, foi sim fundamental para a formalização de Hicks, uma vez que no caso especial em que a TG de Keynes seria válida - o caso da armadilha da liquidez, em

120 motivo transação, o qual Keynes designa de motivos renda e negócios, refere-se àquela parte dos recursos conservados para "garantir a transição entre o recebimento e desembolso da renda" e "para atender contingências inesperadas e às oportunidades imprevistas de realizar compras vantajosas e os de conservar um ativo de valor fixo em termos monetários para honrar uma obrigação em dinheiro" (KEYNES, 1982, p. 157). Já o motivo especulação varia inversamente com a taxa de juros. Reside aí a teoria da determinação dos juros e da preferência pela liquidez. A oferta e demanda por moeda determinam a taxa de juros e a demanda por moeda (preferência pela liquidez é influenciada pela expectativa de juros futuro) (KEYNES, 1982, p. 158-159). 
que a teoria de Keynes se aproximaria da de Marshall - "as equações monetárias dos modelos da 'teoria geral' e clássico' passa[ria]m a ter uma relação funcional comum: variações na demanda por moeda depende[ria]m, exclusivamente, do nível de renda" (FERRARI, 2003, p. 277).

É nesse ponto que Hicks comete uma de suas maiores heresias com relação à Teoria Geral, já que eliminou uma das principais contribuições de Keynes: a teoria da preferência pela liquidez. Colocando de outra forma, Hicks transformou a demanda por moeda (preferência pela liquidez) numa função estável da taxa de juros corrente. Desconsiderou, assim, todo o processo de formação de expectativas e incertezas que havia por trás dessa relação aparentemente simples (LIMA, 1989; LIMA 1992; FERRARI, 2003). Essa interpretação de Hicks está bem caracterizada nos capítulos XIII e XIV do seu livro Valor e Capital. Vejamo-la, de forma resumida, a partir de esclarecedor trecho abaixo:

0 único incentivo possível para reter o dinheiro é aquele que [...] se as pessoas recebem o pagamento das coisas que vendem sob a forma de dinheiro, converter esse dinheiro em letras de câmbio requer outra transação, e a dificuldade de realizar essa transação pode compensar o ganho em juros. Somente se esse obstáculo fosse eliminado, somente se as letras de câmbio seguras pudessem ser adquiridas sem nenhuma dificuldade, é que as pessoas se disporiam a converter to do o seu dinheiro em letras de câmbio, uma vez que não ofereceu nenhum juro. De acordo com as condições de nosso modelo, deve ser a dificuldade de fazer a transação que explica a taxa de juros de certo prazo (HICKS, 1987, p. 138).

Nessa passagem ficaram caracterizados dois elementos da abordagem hicksiana. Primeiro que a moeda não tem as propriedades essenciais destacadas por Keynes, pois ela é considerada uma mercadoria como outra qualquer. A "[...] perfeita substituição é de fato a mais importante propriedade do dinheiro [...e] não há mal em continuarmos considerando o dinheiro [...] como mercadoria-padrão, uma mercadoria selecionada entre as demais para servir de padrão de valor" (HICKS, 1987, p. 123). E, segundo, que a taxa de juros é determinada de acordo com a teoria de fundos emprestáveis.

Quanto à determinação da taxa de juros, a visão de Keynes é diametralmente oposta à de Hicks, enquanto este utiliza a teoria de fundos emprestáveis, aquele utiliza a teoria da preferência pela liquidez. Para Keynes (1982), a taxa de juros é determinada a partir das mudanças nas revisões das expectativas que são construídas em base muito precárias. Desse modo, 
[...] a incerteza das futuras variações das taxas de juros é a única explicação inteligível da preferência pela liquidez que justifica a conservação de recursos líquidos [...]. Segue-se, daí, que entre certo montante [de recursos líquidos] e certa taxa de juros não haverá relação quantitativa definida (KEYNES, 1982, p. 160-161, grifos nossos).

Assim, em Keynes, diferentemente da "síntese", a incorporação da preferência pela liquidez trás consigo a possibilidade dos indivíduos, ante a incerteza com relação ao curso futuro da taxa de juros, demandarem moeda a fim de se proteger ou de especular. Esta moeda, por sua vez, não se transforma em demanda - compra de bens e/ou serviços -, de tal modo que a mesma incerteza que incentiva o entesouramento desestimula os investimentos.

$\mathrm{Na}$ verdade, Hicks inverte a lógica keynesiana ao validar a preferência pela liquidez somente ao caso extremo da armadilha da liquidez, ${ }^{13}$ atrelada a períodos específicos de profunda depressão. Nessa situação, normalmente, as pessoas retêm moeda, provocando um excesso de oferta agregada. ${ }^{14} \mathrm{~A}$ retenção de moeda, nessa ótica, não se deve à incerteza, mas sim às baixas taxas de juros vigentes em tais períodos que reduziriam o custo de retenção da moeda a ponto de estimular a preferência pela liquidez absoluta. Isso, por sua vez, possibilitaria a presença do desemprego involuntário (BARBOSA, 1990). Segundo Hicks (1978, p. 213), "se os custos de se guardar moeda puder ser desprezado, será sempre lucrativo guardar moeda ao invés de a emprestar, se a taxa de juros não for maior que zero [...]". Portanto, somente haveria estímulo para reter moeda quando o custo de retenção da mesma estiver muito baixo. Nessa perspectiva, a armadilha da liquidez teria sido a maior contribuição da TG. Vale ressaltar que a retenção de moeda para Hicks decorreria simplesmente do custo de oportunidade em retê-la não fazendo quaisquer referências aos verdadeiros motivos da preferência pela liquidez descritos por Keynes no capítulo 15 da TG.

Para Hicks, o sistema de equações de Keynes - após a inclusão da renda como um dos determinantes da demanda por moeda proporciona uma conclusão surpreendente, a saber: "um aumento

13 Uma economia se encontra na armadilha da liquidez quando em momentos de grande incerteza, associados a períodos depressivos, a taxa de juros está num nível tão baixo que a política monetária seria incapaz de baixá-la ainda mais. Nesse momento a preferência pela liquidez tornar-se-ía absoluta.

14 A teoria tradicional advoga que caso ocorra excesso de oferta agregada, este seria exaurido pelo funcionamento dos mercados. A lei de oferta e demanda garantiria que o equilíbrio com pleno emprego se restabeleceria a partir da queda dos preços. 
na indução a investir, ou na propensão a consumir, não tenderá a elevar a taxa de juros, porém a aumentar apenas o emprego" (HICKS, 1978, p. 211)..$^{15}$ Hicks ressalta que esta seria apenas uma das possíveis situações do sistema econômico. Portanto, a teoria de Keynes "não é a General Theory", na verdade, podemos "chamá-la, se quisermos, a teoria especial de Keynes" (HICKS, 1978, p. 211).

Ao considerar que a Teoria Geral de Keynes seria um caso particular das economias em depressão, enquanto na situação mais geral - a trajetória de longo prazo - seriam válidas as pressuposições clássicas, ${ }^{16}$ Hicks fez uma junção dessas duas situações num modelo único, cujas equações foram descritas anteriormente (equações 1 , 2 ,3). A partir daí ele construiu o que se tornou universalmente conhecido como modelo IS-LM ou síntese neoclássica. Vejamo-lo agora.

As equações do modelo de equilíbrio "geral" hicksiano $[(\mathrm{M}=\mathrm{L}$ $(\mathrm{Y}, \mathrm{i}) ; \mathrm{I}=\mathrm{I}(\mathrm{Y}, \mathrm{i}) ; \mathrm{I}=\mathrm{S}(\mathrm{Y}, \mathrm{i})$ ], equivalem ao modelo hoje conhecido por IS-LM. ${ }^{17}$ Este se constitui de três mercados: o de bens, o monetário e o de ativos, que, simultaneamente, determinam a renda e a taxa de juros. A primeira das equações determina o equilíbrio no mercado monetário, gerando a taxa de juros, enquanto as duas últimas conformam o equilíbrio do mercado de bens, determinando o nível de renda que é dado pela igualdade entre a oferta agregada e a demanda agregada (DA).

Os componentes e as relações do mercado de bens podem ser expressos da forma que se segue: o consumo varia de forma positiva com a renda e, como requer o modelo hicksiano, o investimento tem relação direta e positiva com a renda e inversa com a taxa de juros. Desconsiderando o comércio com outros países e considerando os gastos do governo como uma variável exógena - de decisão política - chega-se a seguinte equação:

$$
Y=C(Y)+I(Y, i)
$$

Onde, $Y$ = oferta agregada = Renda; $C=$ Consumo; I = Investimento; $\mathrm{i}=$ taxa de juros; e $\mathrm{G}=$ gastos do governo.

A equação 4 é a equação da curva IS - uma das "pernas" do mode-

15 Essa discussão será retomada à frente.

16 A proposição da existência de uma curva de demanda "bem comportada" (efeito substituição > efeito renda) garante que a oferta agregada de longo prazo é igual ao nível de produto potencial. Isso, por sua vez, possibilitaria o equilíbrio com pleno emprego dos fatores (SERRANO \& RIBEIRO, 2004).

170 artigo original de Hicks utiliza a nomenclatura LL e não LM. 
lo hicksiano - que "mostra a relação entre a renda e os juros, que deve ser mantida a fim de que a poupança seja igual ao investimento",18 tendo "a função eficiência marginal do capital determina[do] o valor do investimento a qualquer taxa de juros" e "multiplicador" revelado "que níveis de renda serão necessários para tornar as poupanças iguais àquele valor de investimento" (HICKS, 1978, p. 212). Implicando assim na condição de equilíbrio do mercado de bens (igualdade entre oferta e demanda agregadas). Nessa equação, como o consumo varia positivamente com a renda e como o investimento varia negativamente com a taxa de juros, um aumento nesta afetaria o custo de tomada de empréstimos (custo de oportunidade) para realização de investimentos. De modo análogo, uma redução na taxa de juros ampliaria o investimento (um dos elementos da DA) e, conseqüentemente, a renda por meio do seu multiplicador. Dessa forma, a curva IS é negativamente inclinada $[(\mathrm{d} Y / \mathrm{di})<0]$ quando plotada no espaço $(Y, i)$, já que um aumento nas taxas de juros reduz os investimentos e, por conseguinte, a demanda agregada e o produto da economia.

É preciso esclarecer que Hicks ao sugerir que o nível agregado de investimentos é função estável da renda e das taxas de juros mais uma vez subtraiu um elemento essencial da teoria de Keynes, a saber: os efeitos das expectativas com relação ao curso dos eventos sobre a eficiência marginal do capital. Causa esta primordial na determinação do produto e de suas oscilações no modelo de Keynes, pois sendo a propensão a consumir relativamente estável, as variações no nível de atividade são decorrências, basicamente, das oscilações na taxa de investimento, que, por sua vez, é influenciado, em grande medida, pelas expectativas dos empresários sobre a demanda esperada por seus produtos.

A outra "perna", a curva LM, de inclinação ascendente, relaciona a taxa de juros com o produto, e representa o equilíbrio no mercado monetário, no qual a igualdade entre oferta e demanda por moeda determina a taxa de juros que irá igualar a oferta $(Y)$ à demanda agregadas. Neste mercado, a oferta monetária é exógena, a demanda por moeda pelo motivo transação tem uma relação positiva com renda e a demanda pelo motivo especulação varia negativamente com a taxa de juros ${ }^{19}$ (HICKS, 1978). A curva LM “[...] se inclinará

18 A igualdade entre investimento e poupança, no modelo de Hicks, tem origem na argumentação clássica de que a poupança deve anteceder o investimento, descolando-se completamente da argumentação keynesiana de que a poupança resulta da renda.

19 Neste modelo a taxa de juros é o custo de oportunidade de reter moeda ao invés de outro ativo que renda juros. 
para cima, já que um aumento na renda tende a elevar a demanda por moeda, e um aumento na taxa de juros tende a reduzi-la" (HICKS, 1978, p. 212). O equilíbrio nesse mercado é dado pela igualdade entre oferta e demanda por moeda. Podemos assim representá-lo:

Equação da demanda por moeda: $M^{D}=L(Y, i)$

Oferta monetária: $M^{\mathrm{S}}=\mathrm{M}$

Condição de equilíbrio: $M^{D}=M^{S}$

Apesar de o modelo hicksiano considerar três mercados (bens, monetário e de ativos), a configuração do modelo IS-LM decorre da interação entre apenas dois deles, o de bens (equação 4) e 0 monetário (equação 7). Isso só é possível graças ao uso do método de equilíbrio geral walrasiano. Nas próprias palavras de Hicks (19801981, p. 150),

[...] o equilíbrio geral walrasiano [garante que] se esses dois mercados [0 de bens e o monetário] estiverem em equilíbrio, o terceiro [o de ativos] também deveria estar. Assim, posso concluir que o sistema determina 0 equilíbrio de todo o sistema econômico.

Com a interação entre o mercado de bens e o monetário, a renda e a taxa de juros podem ser determinadas conjuntamente no ponto de interseção das curvas IS e LM, que representa o equilíbrio simultâneo nos dois mercados. Para Mundell (1978), a análise do diagrama de Hicks (figura 1) careceria de uma maior sofisticação. Isto seria possível através da explicitação das condições de oferta e da quebra das pressuposições de níveis de preços e salários constantes desse modelo. Tais elementos foram sendo introduzidos à análise IS-LM ao longo do tempo, principalmente por Modigliani, por Patinkin e pelo próprio Mundell. Graficamente, o modelo IS-LM pode ser representado da segutinte.oformadio IS-LM

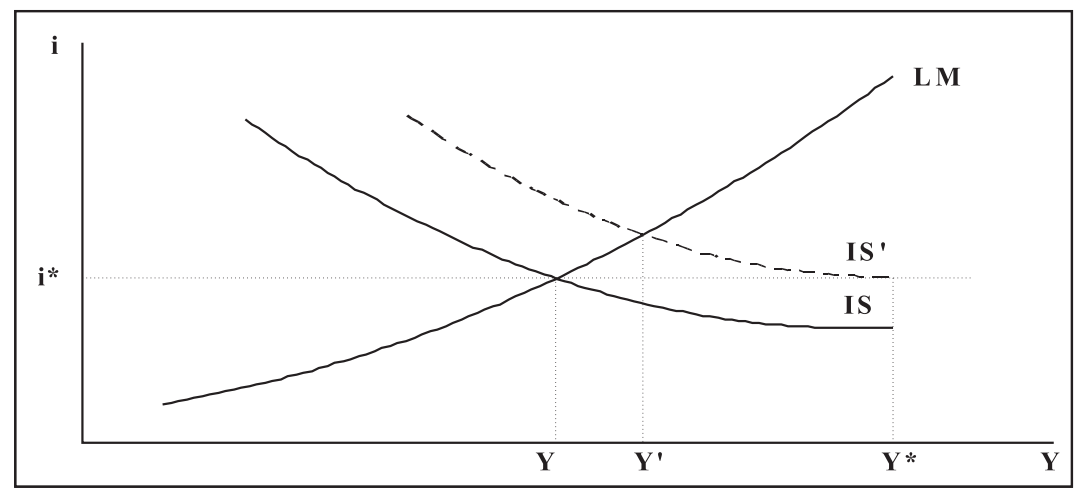


A figura 1 acima mostra que um aumento na demanda agregada provocado, por exemplo, pelo aumento na indução a investir deslocaria a curva IS para a direita, proporcionando um novo nível de produto, maior que o anterior. Esse aumento seria parcialmente limitado pelo aumento na taxa de juros. Dessa feita, um deslocamento da curva IS para a direita aumentaria tanto a renda e o emprego como a taxa de juros.

Ao chegar nesse ponto da discussão, Hicks faz a seguinte pergunta: "Mas [se a teoria de Keynes] é a verdadeira General Theory, como é possível, segundo Keynes, que um aumento na indução a investir não aumentasse a taxa de juros?" (HICKS, 1978, p. 212). No gráfico 1 acima, utilizando-se o instrumental IS-LM, a afirmação de Keynes, questionada por Hicks, somente teria validade para o caso da LM horizontal, já que um aumento da indução a investir (deslocamento da curva IS para a direita) teria efeito somente no nível de produto e do emprego, sendo mantida constante a taxa de juros. ${ }^{20}$ Nesse caso específico o efeito sobre o produto seria "total", ou seja, o efeito multiplicador levaria o produto de Y para o nível Y* (figura 1). Segundo Hicks (1978), uma curva LM horizontal somente existiria no caso extremo de armadilha da liquidez, ${ }^{21}$ ele ainda observa que:

Não apenas é possível mostrar que uma dada oferta de moeda determina certa relação entre renda e juros (expressa por LL) [em nosso caso por LM ]; também será possível dizer algo sobre o formato da curva. Provavelmente tenderá a ser quase horizontal no lado esquerdo e quase vertical à direita. Isso é porque há (1) algum mínimo abaixo do qual a taxa de juros provavelmente não irá, e (embora Keynes não realce isso) há (2) um máximo de nível de renda que possivelmente poderá ser financiado com uma dada quantia de moeda (HICKS, 1978, p. 212).

A partir da figura 2 abaixo se pode inferir que: caso a curva IS cortasse a curva LM bem a esquerda da mesma, no trecho em que ela é horizontal, um aumento tanto na indução a investir como nos gastos governamentais deslocaria a IS para a direita, aumentando o produto e o emprego, permanecendo a taxa de juros em seu nível inicial i'. Esse seria o "caso keynesiano", situação em que o deslocamento da LM para a direita, proveniente de uma expansão na oferta de moeda, não provocaria uma queda na taxa de juros abaixo de i'. A representação desse deslocamento específico ( $L M^{\prime}$ ') é dada pela linha tracejada (HICKS, 1978).

20 Deve-se salientar que na TG a taxa de juros não tem nada a ver com variáveis reais, ela é um fenômeno estritamente monetário, determinada nesse mercado.

21 Apesar de utilizar esse referencial o autor não utiliza esse termo. 
Figura 2. Curva LM de um extremo a outro: do "caso Keynesiano" ao caso da teoria (neo) clássica

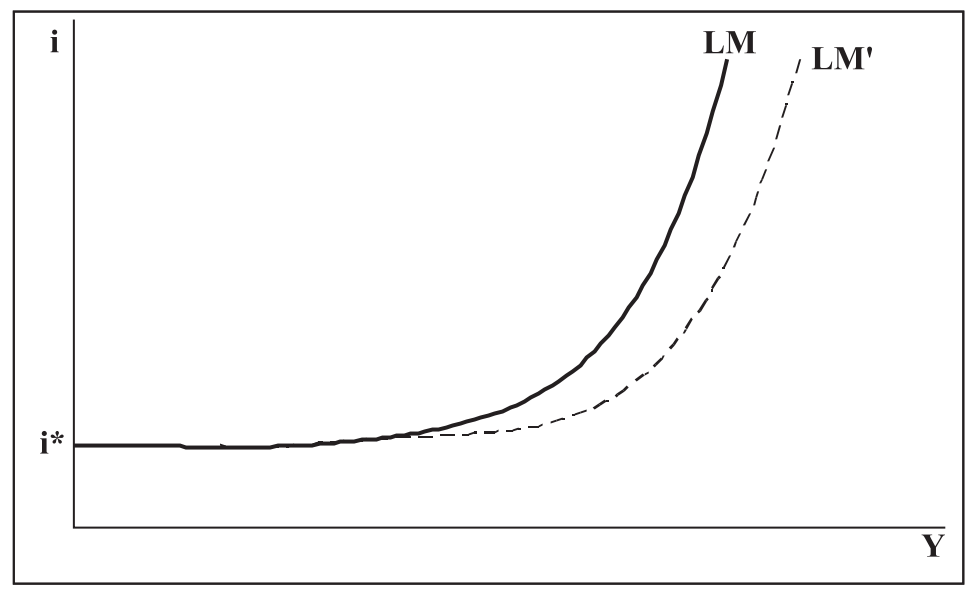

Em outra situação, se a curva IS se posicionar bem a direita da curva LM prevaleceriam as conclusões clássicas, uma vez que um deslocamento da IS para a direita teria seu efeito sobre o produto amortecido pelo aumento na taxa de juros. Decorre daí a formalização final de seu modelo e a junção das teorias keynesiana e clássica.

Em linhas gerais, a síntese neoclássica, através do modelo IS-LM, resume a teoria de Keynes a apenas uma análise de elasticidades. Isso acabou eliminando toda a riqueza analítica da Teoria Geral por não incorporar o papel da incerteza na demanda efetiva, elemento fulcral para a análise de uma economia real em que vivemos (HERMANN, 2003, MISSIO \& OREIRO, 2006). Além disso, a síntese modifica a análise de uma teoria de equilíbrio parcial para uma análise de equilíbrio geral do tipo walrasiana, em que, diferentemente da TG, as posições de equilíbrio do sistema econômico são alcançadas com todas as variáveis sendo determinadas conjuntamente, ou seja, não há como descrevê-lo a partir de mecanismos de transmissão entre as variáveis (LIMA, 2003; PASINETTI apud LIMA, 1992). Desse modo, a noção de determinação simultânea das variáveis, presente na síntese neoclássica, torna a noção de tempo inútil, "[...] no limite equivale a abstrair o tempo" (SILVA, 2003, p. 376).

\subsection{Franco Modigliani e o Efeito Keynes: contribuições e inconsistências}

Franco Modigliani, em seu artigo, Liquidity preference and the theory of interest and money, de 1944, contribuiu para a evolução interpretativa e para a sofisticação do modelo IS-LM hicksiano. Para tanto, ele incorporou explicitamente, em seu modelo, as condições 
de oferta 22 e a flexibilidade dos salários nominais através da construção de duas versões da IS-LM, uma com perfeita flexibilidade dos salários e dos preços (versão clássica ou market clearing) e outra com preços flexíveis e salários rígidos (modelo "keynesiano"). Além dessa contribuição ao IS-LM, destaca-se também sua defesa da dicotomia tradicional entre variáveis reais e monetários, no que diz respeito à determinação da taxa de juros, e o seu pioneirismo na introdução da análise dinâmica ${ }^{23}$ no modelo IS-LM, que foi realizada na seção 10 do seu referido artigo. Em tal análise dinâmica a curva IS e a curva LM assumem a seguinte forma, respectivamente, $Y_{t}=Y_{t-1}-S\left(Y_{t-1}, r_{t}\right)+I\left(Y_{t-1}, r_{t}\right) ; M=L\left(r_{t}, Y_{t-1}\right)(R U B I N, 2004$; MODIGLIANI, 1944).

A despeito da impossibilidade, sugerida por Keynes, da existência de mecanismos que levem o sistema econômico ao pleno emprego, Modigliani (1944) afirma que, na ausência de rigidez de preços e salários, o excesso de oferta de mão de obra (desemprego) seria suprimido pelo movimento de queda dos salários nominais e seus mecanismos de transmissão sobre o preço, a taxa de juros, o investimento e o produto. Assim, a economia retornaria à posição de equilíbrio de pleno emprego. Tal mecanismo constituiu-se em uma das contribuições centrais de Modigliani à síntese neoclássica, sendo este denominado Efeito Keynes. Buscaremos, a seguir, explicar o seu funcionamento e em quais momentos ele não funcionaria.

O caminho do ajustamento da economia ao produto de pleno emprego, por meio do Efeito Keynes, com market clearing, se daria da seguinte forma: numa dada posição de equilíbrio com excesso de mão-de-obra ${ }^{24}$ - que poderia ser fruto, por exemplo, de uma taxa de juros mais elevada do que aquela que igualasse poupança e investimento -, os trabalhadores aceitariam trabalhar por salários

22 As condições de oferta foram explicitadas através das seguintes equações: $Y=P X$ (função de produção); $X=X(N) ; W=X^{\prime}(N) P$ (condição para o máximo lucro); onde $Y$ é renda monetária(produto), P é nível de preço, X é o índice da produção física, W é a taxa de salário (MODIGLIANI, 1944).

23 A formulação da concepção da análise dinâmica no âmbito do mainstrean econômico está pautada no princípio da correspondência desenvolvido por Samuelson (1986) que nos diz: o efeito de uma mudança em um dos parâmetros de um sistema depende da magnitude dessa variação e da forma exata como as demais variáveis respondem à variação original. Entretanto, existem normalmente grandes dificuldades empíricas para detalhar as trajetórias dessas variações, mesmo sendo conhecidas a priori, não se pode de fato derivar um sinal inequívoco para as variações mencionadas sem a suposição da estabilidade do equilíbrio com pleno emprego dos fatores no longo prazo.

240 mercado de trabalho, no modelo de Modigliani, funciona conforme o modelo clássico: o produto da economia é determinado, dado estoque de capital e a tecnologia, pelo trabaIho $[Y=!(N)]$, e o volume de emprego é determinado, por sua vez, pela igualdade entre oferta e demanda de mão-de-obra dependentes do salário real [ $N=N(W / P)]$. 
nominais reduzidos, provocando, por sua vez, uma redução proporcional no nível de preços, uma vez que o trabalho constitui-se de um dos insumos de produção. Essa deflação provocaria uma redução da renda nominal, diminuindo a demanda nominal da moeda para fins transacionais, e impactaria na expansão da oferta de moeda em termos reais, para uma dada oferta nominal de moeda. Isso provocaria uma redução da taxa de juros, o que estimularia o investimento. Com o aumento do investimento, verificar-se-ia uma elevação, por meio do efeito multiplicador, do nível de produto e do emprego até que o excesso de trabalho seja dirimido, restabelecendo assim a condição de pleno emprego. Em termos gráficos, tal ajustamento seria dado pelo deslocamento para direita da função LM, mantendo-se constante a função IS (MODIGLIANI, 1944; SERRANO \& RIBEIRO, 2004; OREIRO, 1997; LIMA, 1989).

Ainda mantendo o suposto de market clearing, Modigliani (1944) apresentou uma situação em que o Efeito Keynes não geraria o equilíbrio de pleno emprego, qual seja, a armadilha da liquidez, situação esta - já definida anteriormente - na qual o investimento é insensível à taxa de juros, o que logicamente invalidaria a seqüência de mudanças supracitadas.

Ao incorporar em sua análise dinâmica o suposto de salários rígidos e preços flexíveis, para uma dada oferta nominal de moeda, Modigliani (1944) chega à conclusão de que a rigidez salarial impede que o sistema econômico, via Efeito Keynes, alcance a situação de plena utilização dos fatores.

A partir, então, das suas duas versões da IS-LM (com market clearing e com rigidez de salários), Modigliani (1944) observou que Keynes não conseguiu provar que equilíbrio com desemprego involuntário seria uma condição normal do sistema econômico, mas que essa situação só aconteceria em casos especiais configurados pela situação da armadilha da liquidez e do suposto de salários rígidos (o caso keynesiano).

It is usually considered as one of the most important achievements of the Keynesian theory that it explains the consistency of economic equilibrium with the presence of involuntary unemployment. It is, however, not sufficiently recognized that, except in a limiting case to be considered later, this result is due entirely to the assumption of "rigid wages" and not to the Keynesian liquidity preference (MODIGLIANI, 1944, p. 211).

Ao assumir tal perspectiva, Modigliani (1944) estabeleceu, a despeito de admitir a existência, em qualquer situação, da preferência pela liquidez, expressa na demanda especulativa por parte dos 
indivíduos, que a demanda especulativa não dependeria da incerteza, mas sim funcionaria como uma proteção contra o risco e seria definida a partir da análise do mercado de títulos. A preferência pela liquidez, juntamente com a oferta monetária, na verdade, seriam os elementos determinantes da taxa de juros de curto prazo, enquanto a taxa de juros de longo prazo seria determinada no mercado de capitais (pelos desejos de poupança e investimento), cuja dinâmica do produto é por ela definida. Sendo assim, Modigliani (1944) remontou a dicotomia (neo)clássica entre setores monetários e reais na determinação da taxa de juros, haja vista que a retenção de moeda pelo motivo especulação seria temporária. Logo essa moeda retornaria ao circuito renda-gasto, com isso, a teoria da preferência pela liquidez não explicaria, como expresso na TG, a existência de desemprego involuntário. Este seria explicado pela existência de mecanismos no mercado de trabalho que tornam rígidos os salários, "[...] na verdade [...] a teoria de salários absolutamente rígidos é uma descrição eficaz do curto prazo, porque no curto prazo os salários são bastante rígidos... [está foi a] revolução científica... [de Keynes]" (MODIGLIANI, 1944, p. 127).

A contribuição científica de Keynes, segundo Modigliani, ficou basicamente circunscrita ao suposto da rigidez de preços, impedindo que o mecanismo de mercado agisse com rapidez. Ao perceber essa limitação temporária do funcionamento da economia, Keynes teria aberto espaço para a consecução de políticas públicas que objetivassem levar a economia a operar no pleno emprego:

Keynes demonstrou que o sistema não se auto-equilibrava com rapidez e que, portanto, havia um papel a ser desempenhado pela intervenção governamental: ou seja, havia espaço para políticas de estabilização tanto monetária quanto fiscais [...][assim] [...]uma parte essencial desse novo paradigma [o keynesiano] foi a conclusão de que as políticas de estabilização eram necessárias. Como o sistema se ajustará lentamente, na melhor das hipóteses, quando se deixar que isso ocorra por si mesmo, há necessidade de uma política pública que aumente a eficiência do sistema (MODIGLIANI, 1988, p. 127-128).

Entrementes, faz-se necessário ressaltar que mesmo que Keynes tenha utilizado, a fim de facilitar sua exposição o suposto da rigidez salarial, esta serviu tão somente para simplificar sua análise, não sendo uma hipótese adotada, mas meramente um artifício, conforme o autor afirma no capítulo 3 da TG:

[...] passaremosa supor que o salário nominal e outros elementos de custo permaneçam constantes por unidade de trabalho agregada. Entretanto, 
essa simplificação, de que maistarde prescindiremos, é introduzida apenas para facilitar a exposição. 0 fato de os salários nominais e de outros aspectos estarem ou não sujeitosa variação em nada altera a natureza do raciocínio (KEYNES, 1982, p. 39).

De fato, tanto a flexibilidade quanto a rigidez de preços e salários não se constituíram em argumentos para justificar o desemprego involuntário. Na verdade, a TG nega a regulação assegurada pelo mecanismo de preços proposta pelo mainstream. A normalidade do desemprego involuntário foi verificada por Keynes a partir dos elementos e da dinâmica da demanda efetiva. Além do que a atuação do Efeito Keynes ${ }^{25}$ - conforme apresentado por Modigliani -, apresenta tantas dificuldades em seus passos lógicos que dificilmente poderia ter validade como um instrumento geral. Quando muito esse efeito pode ser válido em situações amplamente restritivas.

Para justificar tal afirmativa passemos agora a apresentar e a analisar os diversos impedimentos à validação do Efeito Keynes (deflação de preços). Dentre os quais podemos destacar: i) a situação em que ocorra uma distribuição de renda dos salários para os lucros. A redução dos preços pode ser menor do que a dos salários devido ao enfraquecimento do poder de barganha dos trabalhadores no âmbito do conflito distributivo. Como a propensão a consumir dos capitalistas é bem menor do que a dos trabalhadores, conforme Kalecki, essa mudança distributiva da renda leva a uma queda na propensão a consumir da economia em seu conjunto e, conseqüentemente, a queda no consumo poderá ser capaz de amortecer a expansão do investimento (Efeito Keynes-Kalecki); ii) quando a oferta de moeda é endógena, ${ }^{26}$ pois "diante de uma redução dos preços, uma economia [...] terá também uma redução proporcional da oferta de moeda nominal, o que manteria os saldos reais constantes" (SERRANO \& RIBEIRO, 2004, p. 128). Anulando assim, a suposta expansão monetária real, bem como seus efeitos positivos na demanda agregada; iii) caso em que a preferência pela liquidez, diante de um quadro de queda nos preços, aumente mais que a expansão da oferta monetária real; iv) se a economia se encontrar na armadilha da

250 efeito Keynes pode ser sinteticamente expresso, segundo Serrano \& Ribeiro (2004) a partir da seguinte encadeamento de mudanças nas variáveis:

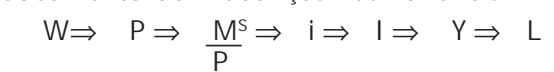

Onde $W$ é o salário nominal; $P$ é o nível de preço; $M^{\text {s }}$ é a oferta monetária nominal; i é a taxa de juros; I é o investimento; Y é o produto; e L é o nível de emprego.

26 Situação em que ante uma redução nos preços, os bancos reajam reduzindo ainda mais a oferta monetária. 
liquidez, problema este já alertado por Modigliani e discutido anteriormente; v) havendo expectativas de nova deflação - diante da queda inicial do nível de preços -, em que o aumento da taxa real de juros esperada compense a queda inicial da taxa de juros nominal. Neste caso, ocorre redução do investimento e, por conseguinte, da demanda agregada (Efeito Keynes-Mundell-Tobin); vi) no caso em que possíveis mudanças negativas na eficiência marginal do capital - decorrente da redução da receita futura esperada, ocasionada pela queda dos preços - não sejam compensadas pela suposta queda na taxa de juros; e vii) quando se verifique uma redistribuição de renda dos devedores para os credores em decorrência do aumento do peso real das dívidas. Considerando que a propensão a consumir dos devedores é maior do que a dos credores, essa mudança distributiva provoca uma queda na propensão a consumir da economia e, por conseguinte, se verificará efeito contraproducente sobre a demanda agregada (Efeito Keynes-Fisher) (SERRANO \& RIBEIRO, 2004; OREIRO, 1997; TADEU LIMA, 1992). A maioria dessas situações são bastante plausíveis e recorrentes numa economia monetária de produção, portanto, o Efeito Keynes tem um alcance muito limitado para gerar a convergência ao equilíbrio de pleno emprego, como sugerido por Modigliani.

\subsection{Don Patinkin e o Efeito Riqueza/Pigou: contribuições e limitações}

O utro importante expoente da síntese neoclássica foi Don Patinkin, em seu artigo Preços flexíveis e pleno emprego, de 1948, ele buscou analisar os efeitos da incorporação das disponibilidades monetárias reais - a partir de Haberler-Pigou ${ }^{27}$ - no sistema analítico keynesiano, tanto numa perspectiva estática como dinâmica, mostrando que a argumentação keynesiana e (neo)clássica têm “[...], na verdade, se aproximado cada vez mais [e] o problema básico que os separa é a rapidez com que o sistema econômico reage às variações de preços" (PATINKIN, 1978, p. 255). Além disso, Patinkin, sobretudo, em seu livro Money, Interest, and Prices, de 1956, ensejou incorporar a micro fundamentação aos fundamentos do modelo IS-LM, uma vez que, para ele, esses fundamentos poderiam ser derivados do modelo de equilíbrio geral walrasiano (PATINKIN, 1978; 1965; RUBIN, 2004).

Patinkin (1978), na parte inicial de seu artigo, explicita a argumentação "keynesiana" sobre a ausência de mecanismos que garantem a igualdade entre os desejos de poupança e de investimento, num nível de renda de pleno emprego: como essas duas decisões são tomadas

27 Para uma discussão aprofundada do Efeito Haberler-Pigou ver Haberler (1937) e Pigou (1943). 
independentes uma da outra não há porque se esperar que elas coincidam num nível de pleno emprego, resultando no desemprego involuntário. Contudo, Patinkin (op.cit.) alerta que essa suposta existência do equilíbrio com desemprego, conforme proposto por Keynes, teria sido fruto de uma especificação errada das funções poupança e investimento. Para ele, estas não poderiam depender apenas do nível de renda, ${ }^{28}$ mas também da taxa de juros e da disponibilidade monetária real mantida pelos indivíduos na economia (Efeito Pigou/ riqueza). Dessa feita, a função poupança correta, expressa por Pigou, deveria ser especificada da seguinte maneira:

$$
\mathrm{S}=\Gamma(\mathrm{i} ; \mathrm{Y} ; \underline{\mathrm{M}} \stackrel{\mathrm{s}}{\mathrm{s}})
$$

Onde i é a taxa de juros; $Y$ é a renda; $\mathrm{M}^{\mathrm{s}}$, a oferta monetária nominal (exógena e constante); e $P$ é o nível de preços.

Para explicar a tendência sistêmica ao pleno emprego dos fatores de produção, Patinkin (1978) verificou a necessidade da inclusão do Efeito Pigou no aparato keynesiano. Este efeito garante que se houver flexibilidade de preços e salários para baixo, sempre haverá um nível de preços, alcançado via tâtonnement capaz de conduzir a economia ao pleno emprego. ${ }^{29}$ O Efeito Pigou, como apresentado por Patinkin, radicaliza a análise de Hicks, já que "em termos estáticos, ou de expectativas constantes, [o sistema econômico] não dependeria da elasticidade da função investimento e, portanto, da função IS, ou da inexistência da armadilha da liquidez, para eventualmente levá-lo a uma situação [inevitável] de equilíbrio de pleno emprego" (LIMA, 1989, p. 45). Cabe destacar que Patinkin (1978) posteriormente trocou a utilização do termo Efeito Pigou por efeito renda ou efeito riqueza, pois tal mecanismo já estaria presente na versão marshalliana da TQM.

Para justificar a suposta convergência ao equilíbrio com plena utilização dos fatores, Patinkin (1978) utiliza-se das teorias de Pigou e Haberler no que diz respeito aos efeitos disponibilidades monetárias reais numa situação de deflação de preços. 0 ajuste via efeito riqueza se processaria da seguinte maneira: numa dada situação de equilíbrio com excesso de mão-de-obra, os trabalhadores aceitariam uma redução em suas remunerações nominais, o que provocaria

28 Vale dizer que a igualdade entre poupança e investimento depende, na análise de Keynes (1982), dentre outras coisas, do nível de renda gerado ex-post, no sistema econômico, pela demanda efetiva.

29 Aqui ele esta incorporando o funcionamento da lei de determinação dos preços de equilíbrio geral de Walras, conforme a definimos. 
uma redução proporcional no nível de preços. Essa queda provocaria uma expansão da oferta de moeda em termos reais, para dada oferta nominal de moeda, aumentando a riqueza dos detentores de moeda, o que, por sua vez, estimularia o consumo. Com o aumento deste, verificar-se-ia uma elevação, por meio do efeito multiplicador, do nível de produto e do emprego até que o excesso de trabalho fosse eliminado. Em outros termos, um aumento no consumo, decorrente da queda do nível de preços, acabaria deslocando a curva de poupança até o ponto em que essa interceptasse a curva de investimentos no nível de renda de pleno emprego. Ao aumentar as disponibilidades monetárias reais, a queda nos preços diminui o desejo de poupança ${ }^{30}$ por motivos que independam da renda futura esperada (taxa de juros). Em termos gráficos, o ajustamento, por meio do efeito riqueza, seria dado pelo deslocamento para direita da função função IS. ${ }^{31}$ (PATINKIN , 1978; SERRANO \& RIBEIRO, 2004; LIMA, 1989; TADEU LIMA 1992; OREIRO, 1997).

A argumentação Pigou-Patinkin requer não somente que a poupança varie inversamente com aumento das disponibilidades (efeito riqueza), mas que "a intensidade [dessa] relação inversa entre as poupanças e as disponibilidades monetárias reais [seja] de tal forma que haja possibilidade de se mudar a função poupança para uma posição em que ela interceptará a função investimento (...)" num nível de renda de pleno emprego. De tal modo, o Efeito Pigou garantiria o pleno emprego (PATINKIN, 1978, p. 267).

É preciso ainda ressaltar que, num contexto de market clearing e de análise estática, o Efeito Pigou-Patinkin só seria garantido nas situações: i) em que Efeito Keynes-Kalecki (conforme apresentado na subseção 2.1.2) fosse nulo; ii) na qual a oferta de moeda fosse exógena; iii) de inexistência da preferência pela liquidez (conforme descrita por Keynes); iv) de abandono das expectativas de deflação num momento em que os preços estão caindo; e iv) na qual o Efeito

30 Nessa perspectiva, os indivíduos poupariam por dois motivos: i) pelo desejo de maior consumo futuro, ou seja, devido à espera de uma taxa de juros positiva que justificasse a troca entre consumo presente e futuro e ii) devido ao desejo de posse (o desejo de acumular riqueza). Logo, quanto maior for essa última em relação à renda, menor seria a poupança destinada para esse fim. Quando a riqueza aumenta, como resultado de uma redução dos preços, a poupança realizada para acumular riqueza (segundo motivo) diminui e os dispêndios aumentam (PATIN KIN, 1978, p. 259-260).

31 Serrano \& Ribeiro (2004, p.134) alertam para o fato de que a inclusão do efeito Pigou nos termos do modelo IS-LM requer "modificar a curva IS para levar em conta o efeito de mudanças na riqueza líquida do setor privado sobre o consumo. Formalmente temos:

$$
I S: Y=\frac{(G+I(r)+j R) " .}{(1-c(1-T))}
$$


estimulante, que uma queda no nível de preços, provoca sobre o credor supere o efeito sobre o devedor desestimulado ${ }^{32}$ (LIMA, 1989; SERRANO \& RIBEIRO, 2004; OREIRO, 1997; TADEU LIMA, 1992).

É muito pouco provável que se verifiquem, numa economia monetária de produção, as situações acima mencionadas. O Efeito Keynes-Kalecki já foi discutido na subseção anterior. A inexistência da preferência pela liquidez é um campo já amplamente discutido em teoria econômica e decorre do fato dos teóricos (neo)clássicos perceberem a moeda como uma mercadoria como outra qualquer. 0 abandono das expectativas de queda de preços em um momento em que os preços estão em queda é uma hipótese muito difícil de se sustentar, já que os agentes ao notarem uma trajetória de queda no nível de preços provavelmente deixariam de gastar neste momento para esperar uma queda ainda maior dos preços, isto impediria 0 aumento da demanda proposta por Pigou. O terceiro pressuposto refere-se à formação de expectativas pelas instituições bancárias, que mesmo diante de um quadro de deflação e de instabilidade deveriam manter a oferta de crédito, situação esta pouco factível. Por último, se o setor privado estiver demasiadamente endividado, pode ser que o efeito riqueza se transforme em efeito pobreza (LIMA, 1989; SERRANO \& RIBEIRO, 2004; OREIRO, 1997; TADEU LIMA, 1992).

O próprio Patinkin (1978), na segunda parte do artigo, alerta para o fato de que o efeito deflacionário (efeito Pigou) teria um comportamento mais ou menos previsível em se tratando de análise estática. No entanto, essa previsibilidade - convergência ao pleno emprego - não seria necessariamente verdadeira num mundo dinâmico. ${ }^{33} \mathrm{Na}$ verdade, uma deflação poderia provocar uma espiral deflacionária de desemprego continuado, em momentos em que o Efeito KeynesMundell-Tobin suplante o Efeito Pigou-Patinkin. Nas palavras do próprio Patinkin (1978, p. 275-276):

320 efeito agregado do gasto (consumo mais investimento) dependerá da distribuição da riqueza entre os agentes, bem como das derivadas parciais do gasto real em relação à riqueza real (LIMA, 1994, p. 17).

33 Antes mesmo da análise de Patinkin a respeito dos efeitos de uma queda no nível de preços, Keynes já havia dedicado grande parte do capítulo 19, da TG, à análise dos efeitos negativos de uma deflação (queda do nível de preços). Nessa situação ele destacou que o aumento da incerteza dos agentes piora as condições de liquidez da economia, afetando negativamente as decisões de investir. Essa decisão sempre tem presente a temporalidade, uma vez que a decisão de investimento é tomada hoje e a produção e venda, e, portanto, a receita somente ocorrem no futuro. Sendo assim, uma redução no nível de preços, acompanhada de expectativas de continuidade da queda reduz a receita esperada pela firma e desestimula a consecução de novos investimentos. (KEYNES, 1982; OREIRO, 2006; TADEU LIMA, 1992, LIMA, 1989). 
Num mundo estático, com estoque constante de moeda, a flexibilidadepreço garante o pleno emprego [...]. Mas, no universo dinâmico real em que vivemos, a flexibilidade-preço com um estoque constante de moeda poderá gerar o pleno emprego após um longo período; ou poderá até levar uma espiral deflacionária de desemprego continuado.

A despeito de Patinkin (1978) considerar a possibilidade de desemprego involuntário em condições de market clearing, Patinkin (1965) incorporou a idéia de pleno emprego no longo prazo, sob uma perspectiva teórica. Retomando a idéia de que a economia convergiria ao estado de pleno emprego. Para tanto, ele articulou a lógica do tâtonnement walrasiano ao modelo IS-LM e resgatou o teorema de Pigou: sempre haverá um nível de preços suficientemente baixo, tal que, se for esperado que continue indefinidamente, irá gerar o pleno emprego. Nesse contexto, "os desequilíbrios da teoria keynesiana passam a ser interpretados como desequilíbrios dinâmicos do sistema de equilíbrio geral walrasiano" (FERRARI FILHO, 2003, p. 278).

Em síntese, a introdução do Efeito Pigou ou efeito riqueza no instrumental IS-LM buscou dar sustentação teórica à inevitabilidade do pleno emprego. Os teóricos da síntese argumentam que não caberia, logicamente, dentro de uma economia em que os mecanismos de mercados operam livremente, a existência de um equilíbrio com desemprego involuntário. Qualquer ponto onde houvesse algum excesso de oferta não seria um ponto de equilíbrio e as forças de mercado tratariam de exauri-lo.

As interpretações desenvolvidas por Hicks, Modigliani e Patinkin a respeito da TG concluem que a grande contribuição de Keynes teria sido a possibilidade temporária de a economia operar com desemprego involuntário, haja vista a rigidez de preços e/ou salários e outras imperfeições efêmeras. Dessa forma, a Teoria Geral não teria se constituído numa revolução científica, mas sim numa explicação para os lag's da teoria clássica. E ainda que, sob a hipótese de flexibilidade de preços e salários, não haveria motivos para a economia permanecer com excesso de oferta de mão-de-obra, de tal sorte que o Efeito Pigou e/ou o Efeito Keynes levariam à convergência. Por fim, podemos assim resumir o tratamento dado pelos teóricos da síntese neoclássica à Teoria Geral de Keynes:

[...] A síntese neoclássica, ao transpor a economia de Keynes para um sistema de equilibro geral, violou um princípio organizador fundamental em Keynes, ou seja, a rejeição da noção de ajuste automático e simultâneo entre os mercados [...] em que to das as decisões econômicas relevantes 
estão nas mãos dos capitalistas [em contraposição à síntese em que o nível de emprego é determinado pelas decisões maximizantes de trabalhadores e firmas] (LOPES, 1992, p. 132).

\section{Consideraç̧ões Finais}

Há cerca de setenta anos, Keynes, na TG, rejeitou os principais axiomas e os princípios basilares da teoria (neo)clássica, do mundo da lei de Say, até então predominante. Devemos ressaltar que o ponto essencial da formulação de Keynes reside na idéia de que a demanda esperada é o principal determinante das decisões de investimento e, por conseguinte, do nível de emprego. Nos capítulos 2 e 3 da TG, contrapondo-se à teoria (neo)clássica, Keynes afirma que os trabaIhadores não controlam o nível de emprego, em outras palavras, o nível de emprego não é determinado pela interação entre oferta e demanda de mão-de-obra, mas sim puramente pelas condições de demanda esperada pelas firmas. Estas, guiadas pela possibilidade de venderem seus produtos com lucro, contratam mais trabalhadores e determinam o nível de emprego da economia. ${ }^{34}$ Neste ponto levantado por Keynes, ressalta-se a assimetria de poder entre os agentes econômicos, condição esta sem relevância para a síntese neoclássica. $\mathrm{Na}$ lógica de Keynes, o desemprego persiste involuntário mesmo se os trabalhadores se dispuserem a trabalhar por menores salários

34 Essa argumentação, por si só, seria suficiente para desmoronar a hipótese de determinação do salário real e do nível de emprego sustentada pela teoria tradicional, qual seja, "que as negociações salariais entre trabalhadores e empresários determinam o salário real, de tal modo que, [...] os últimos poderiam se desejassem, fazer coincidir os seus salários reais com a desutilidade marginal do volume de emprego oferecido pelos empregadores ao dito salário" (KEYNES, 1982, p. 29). No capítulo 2 da TG, além de apresentar os postulados da teoria clássica, Keynes (1982) apresentou rigorosos argumentos que invalidam o segundo postulado da teoria clássica (os trabalhadores aceitam oferecer certo volume de emprego até o ponto onde a utilidade do salário se iguala à desutilidade marginal desse mesmo volume de emprego). Dentre os argumentos apontados por Keynes, destacam-se primordialmente: i) o fato de que são as empresas que definem o volume de mão-de-obra a contratar e, somente em raríssimas exceções - consideradas apenas teoricamente -, os trabalhadores teriam algum poder de barganhar salários. No caso geral, a oferta de mão-de-obra é uma curva perfeitamente inelástica em relação aos salários vigentes (p. 30); ii) a segunda observação refere-se ao comportamento dos trabalhadores, estes normalmente negociam (dentro de restritas possibilidades) salários nominais e não salários reais, sendo os primeiros pouco suscetíveis a cortes, enquanto seria impraticável se opor a uma redução do salário decorrente da redução do poder aquisitivo do dinheiro (p. 27-29; p. 31); iii) um terceiro argumento que muito contribui para desmontar a concepção clássica da oferta de mão-deobra é a idéia implícita de que em momentos de recessões os trabalhadores abandonariam seus empregos para usufruir de uma vida de lazer, ou que, diante de uma queda no salário real, trabalhadores desempregados, desistiriam de procurar emprego ao novo salário vigente (p. 28; 30). Essas suposições, segundo Wells (1987, p. 81) equivalem a pensar o mundo como sendo "densamente povoado por pessoas maravilhosamente excêntricas". 
que os de mercado, pois não são os salários elevados que condicionam a existência do desemprego involuntário, mas sim as condições da demanda esperada e da incerteza. Para Davidson apud Nunes Ferreira (2003, p. 106) "trabalhadores desempregados podem [...] reduzir salários monetários até que estejam à míngua sem alterar um iota a 'correta' decisão de contratação do empreendedor que maximiza lucro, a menos que os salários monetários induzam um aumento da receita esperada". Dessa feita, uma queda no nível de salário poderia, ao contrário da visão tradicional, desestimular novas contratações, quer seja por ser o salário um elemento da demanda quer seja pela incerteza inerente a um processo depressivo (espiral deflacionária).

Por outro lado, os autores da síntese neoclássica defendem que a plena flexibilidade de preços e salários, no longo prazo, garante que as forças endógenas do sistema - movimento da oferta e da demanda - seriam capazes de levar a economia para um equilíbrio de pleno emprego. Na verdade, Keynes (1982, p. 231) dispensou a exigência de rigidez de preços para explicar a presença do desemprego involuntário. Para ele é a tomada de decisões dos agentes, refletida pelo princípio da demanda efetiva (PDE) e pela incerteza nos processos decisórios que justificam a existência do desemprego. Assim, o PDE garante que a renda e o emprego são determinados pelas quantidades de bens e serviços que são produzidos e levados ao mercado com base em uma expectativa de demanda futura feita pelos empresários (SICSÚ, 2003, p. 163; TADEU LIMA, 2003, p. 312; HERMANN, 2006, p. 4). Nunes Ferreira (2003, p. 107) expressa esse ponto de vista:

[0] princípio da demanda efetiva, e com ele a determinação do nível de emprego, somente pode ser compreendido à luz de uma teoria da tomada de decisão do agente proprietário de riqueza. Esse agente, no entanto, se move em um ambiente macroeconômico incerto, que sabe determinado pelas suas próprias ações, pelas ações dos outros agentes e pelas instituições que os circundam. Este é o ponto distintivo do construto de Keynes e dos Pós-keynesianos.

Como existe um hiato temporal entre o momento da formulação das expectativas e, portanto, da produção e o instante em que os produtos são levados ao mercado, as expectativas poderão ser frustradas. A não efetivação das expectativas, que se reflete em uma venda menor do que a esperada, fará com que os agentes revisem-nas de tal maneira que o nível de produção e de emprego sejam redefinidos. Assim sendo, o princípio da demanda efetiva constitui uma formulação concreta, dentro do propósito de Keynes, em fornecer uma 
teoria alternativa, no que tange aos determinantes do nível de atividade. Ao PDE está subordinado praticamente todo o sistema teórico de Keynes, dentre os quais, a determinação do produto, do emprego, da taxa de juros e da preferência pela liquidez (LIPKIN, 1990, p. 25). Em linhas gerais, na economia em que vivemos o nível de atividade econômica, bem como suas flutuações, é determinado pelas decisões de gastos dos agentes econômicos, ou seja, são endógenas ao próprio funcionamento da economia, conforme afirmou Keynes (1984, p. 168) "[...] as expansões contêm, em seu bojo, as sementes de sua própria destruição", não decorrendo, portanto, de choques exógenos como na teoria (neo)clássica. Além do que não há mecanismos endógenos que conduzam a economia ao pleno emprego.

Em suma, o esforço envidado por Keynes, na TG, consistiu-se, portanto, em estabelecer um vínculo entre produção e gastos em termos de uma relação geral de determinação da primeira variável pela última. Sendo assim, a discussão sobre rigidez ou flexibilidade de preços e salários, característica central na síntese neoclássica, não é de grande relevância na leitura de Keynes aqui adotada. Nesta, numa investigação sobre as propriedades do sistema econômico, referentes às relações de causalidade, envolvendo a procura como determinante do nível de atividade econômica, preços rígidos implicam somente a cessação de sua variabilidade (KEYNES, 1982, p. 39; VERNENGO, 1995, p. 72; POSSAS, 1987).

Nesse sentido, este artigo buscou apresentar, numa perspectiva crítica, os elementos basilares da síntese neoclássica, destacando a contribuição e os problemas lógicos do modelo IS-LM de Hicks, as limitações da incorporação do Efeito Keynes ao sistema econômico real, conforme desenvolvido por Modigliani, bem como as dificuldades de inclusão do Efeito Pigou ao modelo desenvolvido por Patinkin, tanto em sua perspectiva estática quanto dinâmica. Na verdade, argumentou-se aqui que a síntese distorceu a visão de Keynes acerca do funcionamento da economia capitalista, uma vez que ela eliminou as principais contribuições deste último (teoria da demanda efetiva e a incerteza nos processos decisórios).

\section{Referências Bibliográficas}

BARBOSA, E. S. O princípio de Say como critério de ortodoxia econômica. 1990. Dissertação (Mestrado). Departamento de Economia da Universidade de Brasília. Braślia/DF, maio de 1990.

BLANCHARD, O.J . Macroeconomia: teoria e política. Rio de J aneiro, Campus, 1999.

CARVALHO, F.C Mr. Keynes and the Post Keynesians. Edward Elgar Publishing Ltd., 1992b. 
CARVALHO, F.C. Moeda, Produção e Acumulação: Uma Perspectiva Pós-Keynesiana. In: SILVA, M. L. F. (org.) Moeda e Produção: Teorias Comparadas. Brasília: Ed. UNB, 1992a.

DAVIDSON, P. Colocando as evidências em ordem: macroeconomia de Keynes versus velho e novo keynesianismo. In: LIMA, G. T.; PAULA, L. F.; SICSÚ, J. (Org.). Macroeconomia Moderna. Rio de J aneiro: Campus, p. 35-64, 1999. $\overline{1} \overline{9} \overline{8}$. . Money and the real world. Houndmills, Basingstoke: the Macmillan press, . Resgatando a revolução keynesiana. In: LIMA, G.T. \& SICSÚ, J . (orgs.) Macroeconomia do emprego e da renda: Keynes e o keynesianismo. Barueri/SP, Manole, 2003.

FERRARI, F.F. Keynesianos, monetaristas, novo-clássicos e novos-keynesianos: uma leitura pós keynesiana. In: LIMA, G.T. \& SICSÚ, J . (orgs.) Macroeconomia do emprego e da renda: Keynes e o keynesianismo. Barueri/SP, Manole, 2003.

HABERLER, G. Prosperity and depression. Geneva: League of Nations, 1937.

HERMANN, J. Ascensão e queda da política fiscal: de Keynes ao "autismo fiscal" dos anos 1990-2000. In: XXXIV Encontro Nacional de Economia, 2006, Salvador/Ba. Anais... Salvador, 2006.

O modelo de racionamento de crédito e a política monetária novo keynesiana: uma análise crítica. In: LIMA, G.T. \& SICSÚ, J . (orgs.) Macroeconomia do emprego e da renda: Keynes e o keynesianismo. Barueri/SP, Manole, 2003.

HICKS, J. IS-LM: an explanation. J ournal of Pos Keynesian Economics, v. 3, n. 2, p. 139 154, 1980-1981, winter.

- Valor e Capital. São Paulo, Nova cultural, 1987.

. Keynes e os "clássicos": Uma interpretação sugerida. In: SHAPIRO, E. (org.) Ānálise macroeconômica: Leituras Selecionadas. São Paulo, Atlas, 1978.

KEYNES, J . M. A teoria geral do emprego (1937). In: SZM RECSANYI, T. J ohn Maynard Keynes: economia. São Paulo: Ática, p. 167-179, 1984.

. A teoria geral do emprego, do juro e da moeda. São Paulo. Atlas, 1982.

LIMA, G. T. Em busca do tempo perdido: a recuperação póskeynesiana da economia do emprego de Keynes. 160 Premio BNDES de Economia. Editado pelo gabinete da presidência - Departamento de relações institucionais, Rio de J aneiro, 1992.

. O império contra-ataca: a macroeconomia de Keynes e a síntese neoclássica. In: LIMAA, G.T. \& SICSÚ, J. (orgs.) Macroeconomia do emprego e da renda: Keynes e o keynesianismo. Barueri/SP, Manole, 2003.

LIMA, L. A. O. Alguns aspectos críticos da "nova macro keynesiana". Revista de economia política, v. 14, n. 2 (54), abril-junho, 1994.

. As funções IS-LM e a "neoclassização" do pensamento de Keynes. Revista de Ëconomia Política, v. 9, n. 2, abril-julho, 1989.

LIPKIN, S. M. O princípio da demanda efetiva na controvérsia Keynes versus "clássicos". 1990. 649f. Dissertação (mestrado em economia) - Universidade Federal do Rio de J aneiro. Rio de janeiro, 1990.

LOPES, C. M. A síntese neoclássica. In: AMADO, A. M.; FALCÃO, M. L. S. (orgs.) M oeda e Produção: teorias comparadas. Brasília/DF: Editora Universidade de Brasília, 1992. p.129-138.

LOPES, L.M. \& VASCONCELLOS, A.S. (orgs.) Manual de Macroeconomia: nível básico e intermediário. São Paulo: Atlas, 2000. 
MANKIW, N.G. Macroeconomia. Rio de J aneiro: J TC, 1995.

MISSIO, F. \& OREIRO, J . L. Equilíbrio com pleno emprego e equilíbrio com desemprego em um contexto de preços e salários flexíveis: o debate entre Keynes e os (neo) clássicos. Mimeo, UFPR - Fevereiro, 2006.

MODIGLIANI, F. Conversa com economistas neo-keynesianos: a velha geração. In: KLAMER, A. Conversas com economistas: os novos economistas clássicos e seus opositores falam sobre a atual controvérsia em macroeconomia. São Paulo, Pioneira, Universidade de São Paulo, p. 119-131, 1988.

MODIGLIANI, F. Liquidity preference and the theory of interest and money. Econometrica, V. 12, 1944.

MUNDELL, R. A. Uma exposição de algumas sutilezas do sistema keynesiano. In: SHAPIRO, E. (org.) Análise macroeconômica: Leituras Selecionadas. São Paulo, A tlas, 1978

NUNES FERREIRA, A. Teoria macroeconômica e fundamentos microeconômicos. 2003. 134 f. Tese (Doutorado em economia) - Unicamp, Campinas, São Paulo, 2003.

OREIRO, J. L. Flexibilidade Salarial, Equilíbrio com Desemprego e Desemprego de Desequilíbrio. Revista Brasileira de Economia, v. 51, n. 3, 1997.

PATIN KIN , D. M oney, interest, and prices: an integration of monetary and value theory. N ova York, Harper \& Row Publishers, 1965.

. Preços flexíveis e pleno emprego. In: SHAPIRO, E. (org.) Análise macroeconômica: Leituras Selecionadas. São Paulo: ed. Atlas, p. 254-280, 1978.

PIGOU, A.C. The classical stationary state. The Economic J ournal, v. 53, n. 212, p. 343351, Dec. 1943.

POSSAS, M. L. A dinâmica da economia capitalista: uma abordagem teórica. São Paulo: Editora Brasiliense, 1987.

RUBIN, G. Patinkin on IS-LM : an alternative to Modigliani. History of Political Economy, v. 36, Duke University Press, Annual Supplement, p.190-216, 2004.

SAMUELSON, P. Fundamentos da análise econômica. São Paulo: N ova cultural, 1986. 380p. (Coleção OsEconomistas)

SERRANO, F. \& RIBEIRO, R. T. Notas críticas sobre a curva de demanda agregada. Economia-Ensaios, Uberlândia, v. 18, n. 2, p. 123-143, dez. 2004.

SILVA, A.C.M. A economia de Keynes e a "armadilha do equilíbrio". In LIMA, G. T. \& SICSÚ, J. (orgs.) Macroeconomia do emprego e da renda: Keynes e o keynesianismo. Barueri/SP: ed. Manole, 2003

SICSÚ, J . \& MENDONÇA, H. F. Deflação, recessão e recuperação econômica: um modelo keynesiano. Revista Brasileira de Economia, v. 54, n. 4, 2000.

SICSÚ, J. Keynes e os novos-keynesianos. In: LIMA, G.T. \& SICSÚ, J. (Org.) Macroeconomia do emprego e da renda: Keynes e o keynesianismo. Barueri/SP: Manole, p. 147-179, 2003.

VERNENGO, M. Método, moeda e demanda efetiva: algumas considerações sobre a posição keynesiana na história do pensamento econômico. 1995. 104f. Dissertação (Mestrado em Economia) - Universidade Federal do Rio de J aneiro. Rio de janeiro, 1995. W ELLS, P. Economia da libertação: a rejeição de Keynes às teorias clássicas de emprego e demanda agregada. In: Ensaios de teoria pós-keynesiana. Universidade Federal do Ceará. Imprensa Universitária. Fortaleza, p. 75-93, 1987.

YOUNG, W. Interpreting Keynes: The IS/LM Enigma. Boulder, Colorado, Westview Press, Oxford, Basil Blackwell, 1987. 
